\title{
Formation of self-ordered porous anodized alumina template for growing tungsten trioxide nanowires
}

\author{
Tajamal Hussain • Asma Tufail Shah • Khurram Shehzad • Adnan Mujahid • \\ Zahoor Hussain Farooqi • Muhammad Hamid Raza • Mirza Nadeem Ahmed • \\ Zaib Un Nisa
}

Received: 26 September 2014/ Accepted: 1 December 2014/Published online: 18 December 2014 (C) The Author(s) 2014. This article is published with open access at Springerlink.com

\begin{abstract}
Uniform porous anodized aluminum oxide (AAO) membrane has been synthesized by two-step anodization for fabricating tungsten trioxide $\left(\mathrm{WO}_{3}\right)$ nanowires. Under assayed conditions, uniform porous structure of alumina $\left(\mathrm{Al}_{2} \mathrm{O}_{3}\right)$ membrane with long range ordered hexagonal arrangements of nanopores was achieved. The self-assembled template possesses pores of internal diameter of $50 \mathrm{~nm}$ and interpore distance $\left(d_{\text {int }}\right)$ of $80 \mathrm{~nm}$ with a thickness of about $80 \mu \mathrm{m}$, i.e., used for fabrication of nanostructures. $\mathrm{WO}_{3}$ nanowires have been fabricated by simple electroless deposition method inside $\mathrm{Al}_{2} \mathrm{O}_{3}$ nanopores. SEM images show tungsten trioxide nanowire with internal diameter of about $50 \mathrm{~nm}$, similar to porous diameter of AAO template. XRD results showed that nanowires exist in cubic crystalline state with minor proportion of monoclinic phase.
\end{abstract}

T. Hussain $(\bowtie) \cdot$ A. Mujahid · Z. H. Farooqi ·

M. H. Raza · Z. U. Nisa

Institute of Chemistry, University of the Punjab,

Lahore 54590, Pakistan

e-mail: tajamalhussain.chem@pu.edu.pk;

tajamalhussain.chem@pu.edu.com

A. T. Shah $(\bowtie)$

Interdisciplinary Research Centre in Biomedical Materials, COMSATS Institute of Information Technology,

Lahore 54000, Pakistan

e-mail: asmashah_buct@yahoo.com

K. Shehzad

Center for Nano and Micro Mechanics, Tsinghua University, Beijing 100084, China

M. N. Ahmed

Department of Applied Chemistry, GC University Faisalabad, Faisalabad 38000, Pakistan
Keywords Anodic aluminum oxide $\cdot$ Anodization Tungsten trioxide $\cdot$ Nanowire $\cdot$ Electroless deposition

\section{Introduction}

Porous anodized alumina (PAA) is one of the most exciting nanostructured material which has gained significant attention for applications in gas separation [1], drug delivery [2], bone fixation [3], and a template for nanostructures formation $[4,5]$. PAA membrane consists of an ordered hexagonal arrangement of cells with a central pore per cell that elongates from top to bottom of the layer, resembling a honeycomb network [6, 7]. Porous alumina template is formed by the anodization of aluminum metal, which is a self-organized material used for depositing layer of nanoporous oxide [8]. These pores are used as template for synthesis/growth of one dimensional (1D) nanostructure and thus, their degree of ordering plays an important role in the homogeneity of the resulting nanomaterials. Therefore, it is important to understand and control the pore size and morphology of PAA membranes [9-11]. The anodization conditions such as voltage, current density, $\mathrm{pH}$, temperature, and time of anodization play a critical role in controlling the textural properties of AAO membrane in specific electrolyte $[12,13]$.

Tungsten trioxide $\left(\mathrm{WO}_{3}\right)$ is one of the most promising inorganic materials, which exhibits excellent electrochromic, photochromic, and gasochromic properties and is widely used in electrochemical, solar energy, optical modulation, flat panel displays, and sensors applications $[14,15] . \mathrm{WO}_{3}$ nanowires are mainly used for sensing various nitrogen oxides, while nanoporous $\mathrm{WO}_{3}$ is used for sensing alcohol $[16,17]$. The most important feature of sensor based on $\mathrm{WO}_{3}$ nanowires is that their response is not 
affected by the extent of humidity. Diverse forms of $\mathrm{WO}_{3}$ nanowires such as monoclinic [18], hexagonal [19], and cubic [20] have recently been synthesized by adopting different methodologies. Various methods such as electrochemical deposition, electroless deposition, electrophoretic deposition, template filling, sol-gel method, and pressure injection techniques have been employed for the fabrication of tungsten trioxide on template. Among different techniques, electroless deposition is a straightforward and room temperature method for growing nanostructures. It is actually a deposition process that involves the coating of a material on template surface using a chemical agent without applying electric current. Herein, we report the synthesis of highly ordered hexagonal porous anodized alumina structure using two-step anodization, the two-step anodization is a favorable method for generating template nanostructures of improved morphology and for fabricating cubic tungsten trioxide nanowires by simple electroless deposition method.

\section{Materials and methods}

\section{Materials and chemicals}

High purity (99.99\%) aluminum foil was used for fabrication of PAA membrane. All chemicals and solvents were of analytical grade and were used without any further purification. The anodization voltage was selected after plotting voltage versus time plot.

Fabrication of anodized aluminum oxide templates

For anodization, aluminum foil was degreased with acetone to remove any dirt or grease if present. Then, to minimize the mechanical stress and to change grain boundaries, it was subjected to annealing at $450{ }^{\circ} \mathrm{C}$ in a furnace for $5 \mathrm{~h}$ at the heating rate of $1{ }^{\circ} \mathrm{C} / \mathrm{min}$. The oxides were removed by chemical washing using dilute oxalic acid solution and rinsed with deionized water. Annealed foil was polished electrically in a mixture of ethanol and perchloric acid (1:4 by volume) at $12 \mathrm{~V}$ for $3 \mathrm{~min}$ at $10{ }^{\circ} \mathrm{C}$.

PAA was fabricated by two-step anodization that was carried out in a specially designed two electrodes cell system using graphite as counter electrode. The distance between two electrodes was $25 \mathrm{~mm}$. First anodization was carried out at $40 \mathrm{~V}$ and $5{ }^{\circ} \mathrm{C}$ temperature for $300 \mathrm{~min}$ with constant stirring in $0.3 \mathrm{M}$ oxalic acid electrolyte. Then, anodized aluminum substrate was washed with chromic acid and phosphoric acid mixture for $30 \mathrm{~min}$ to remove oxide layer. In the second anodization, the substrate was again anodized at $40 \mathrm{~V}$ for $120 \mathrm{~min}$ at $5{ }^{\circ} \mathrm{C}$ in $0.3 \mathrm{M}$ oxalic acid with constant stirring. After second anodization, the membrane was immersed in phosphoric acid for $90 \mathrm{~min}$ to increase the width of pores.The morphology of all synthesized membranes was studied by Hitachi S-4700 scanning electron microscope (SEM) using.

Generation of tungsten trioxide nanowire by electroless deposition method

Self-assembled PAA was used as template for fabrication of nanowires. The membrane was sonicated in sensitizing mixture of $0.3 \mathrm{wt} \% \mathrm{SnCl}_{2}$ and $2.5 \mathrm{wt} \% \mathrm{HCl}$. The sensitization time was optimized to $5 \mathrm{~min}$ after a number of experiments, since prolonged dipping of AAO template in $\mathrm{SnCl}_{2}$ solution results in dissolution of the template. The membrane was rinsed with deionized water and immersed in $0.1 \mathrm{wt} \% \mathrm{PdCl}_{2}$ and $1 \mathrm{wt} \% \mathrm{HCl}$ mixture for $3 \mathrm{~min}$. The template was again rinsed with deionized water. The sensitized and activated PAAs were immersed in deposition bath for $30 \mathrm{~min}$ and washed with deionized water. The composition of deposition bath was sodium tungstate $2.3 \times 10^{-2} \mathrm{M}$, Hydrazine hydrate $3.1 \times 10^{-1} \mathrm{M}$, sodium potassium tartarate $1.77 \times 10^{-1} \mathrm{M}$, and acetic acid $10^{-2} \mathrm{M}$. The $\mathrm{WO}_{3}$ nanowires were deposited in the pores of alumina membrane and characterized by powder XRD using Rigaku D/Max 2500 VBZ+/PC diffractometer. In order to remove aluminum oxide, the template is dipped in $5 \mathrm{wt} \% \mathrm{NaOH}$ for $5 \mathrm{~min}$ at $25^{\circ} \mathrm{C}$. Then, to remove $\mathrm{Al}_{2} \mathrm{O}_{3}$ residues, the template was thoroughly washed with deionized water for $2-3$ times. The samples were analyzed by SEM.

\section{Result and discussion}

Measurement of current density for anodization

Nanotexturing and self-ordering of pores of anodized alumina mainly depend upon voltage and current density used during the anodization. Optimized value of voltage was measured viz. $40 \mathrm{~V}$. This value agrees with the voltage corresponding to self-ordered anodizing at constant current available in literature [21, 22]. Therefore, anodization was carried out in electrolytic solution of $0.3 \mathrm{M}$ oxalic acid at the voltage of $40 \mathrm{~V}$ at $5{ }^{\circ} \mathrm{C}$ temperature. The variation of current densities with anodization time for both first and second steps of anodization is graphically represented in Fig. 1. Figure 1 shows that both steps consist of three major parts; (i) formation of barrier oxide layer, (ii) generation of pores, and (iii) growth of pores. The main difference between 1st and 2nd step anodization is quite clear from the graph. For 1st step anodization, the time for the minimum and constant current density is greater than second step (first two parts). The reason is that in 1 st step 


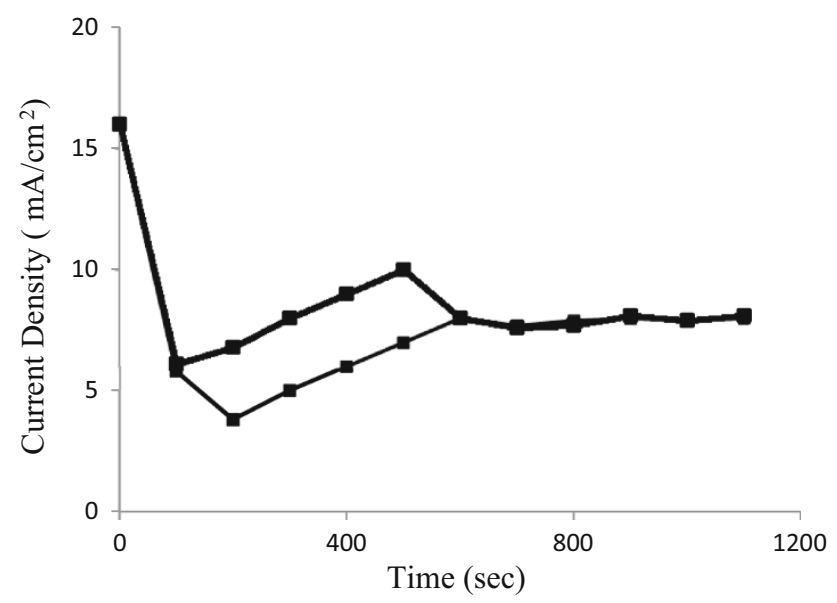

Fig. 1 Plot of current density $\left(\mathrm{mA} / \mathrm{cm}^{2}\right)$ versus time (s) for first (thin) and second (thick) step of anodization at constant voltage of $40 \mathrm{~V}$

anodization pores begin to form, and the generation and growth of these pores take more time compared to 2nd step anodization where already nanotexture exists in aluminum surface [23]. Treatment with phosphoric and chromic acids for the removal of oxide layer results in the formation of concave-shaped spots on the surface of aluminum template. These nuclei act as a base for the generation of new pores during 2nd step. The constant current density in this case was $8 \mathrm{~mA} \mathrm{~cm}{ }^{-2}$ obtained from current density versus time graph for first and second anodization at $V_{\text {plateau }}=40 \mathrm{~V}$ and was used for two-step anodization.

Surface morphology of anodized aluminum oxide (AAO) membrane

SEM was used to study the morphology of PAA membrane. Figure 2a, b, and $\mathrm{c}$ represent SEM images for anodized aluminum oxide template after two-step anodization. SEM image shows that membrane was highly ordered with uniform distribution of perfect hexagonal porous structure having diameter about $50 \mathrm{~nm}$. The interpore distance $\left(d_{\text {int }}\right)$ was also homogenous and equal to about $80 \mathrm{~nm}$ and the thickness of PAA film was about $80 \mu \mathrm{m}$ (Fig. 2c). The order domain covers almost $85 \%$ of the surface of aluminum substrate, while the density of pores was also high. These results were in accordance with current density versus time plot. However, according to some reports [23, 24], longer first anodization could result in increased voltage due to enrichment of $\mathrm{Al}^{+3}$ and change the local $\mathrm{pH}$ due to electrochemical reactions; thus, leading to short range ordering. However, in present experiments, the continuous stirring kept the voltage constant avoiding any change in etching rate and, therefore, resulted in homogeneous structure with large domain of hexagonal ordered structure.
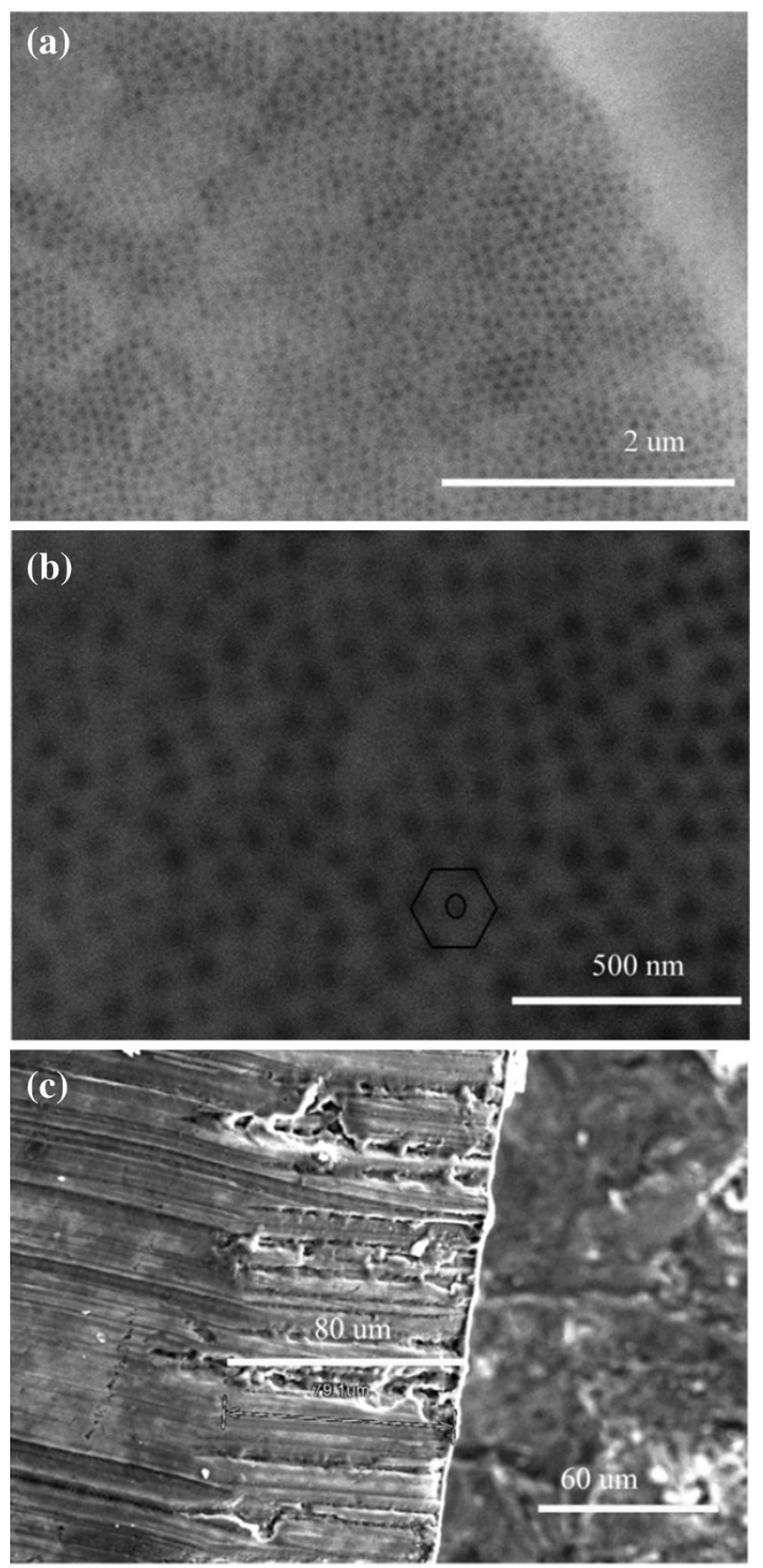

Fig. 2 a and b On-top SEM image of PAA after two step anodizing with two different zoom $\mathbf{c}$ cross sectional view of PAA

\section{Tungsten trioxide nanowire}

$\mathrm{WO}_{3}$ nanowires were synthesized by electroless deposition method at room temperature. Hydrazine hydrate $\left(\mathrm{N}_{2} \mathrm{H}_{4}\right.$ $\mathrm{H}_{2} \mathrm{O}$ ) was taken as a reducing agent, sodium potassium tartarate as a complexing agent, and acetic acid was used to maintain $\mathrm{pH}$. The mechanism of electroless deposition is as follows:

At elevated temperature, hydrolysis of stannous chloride results in the formation of $\mathrm{Sn}(\mathrm{OH})_{4}$ 

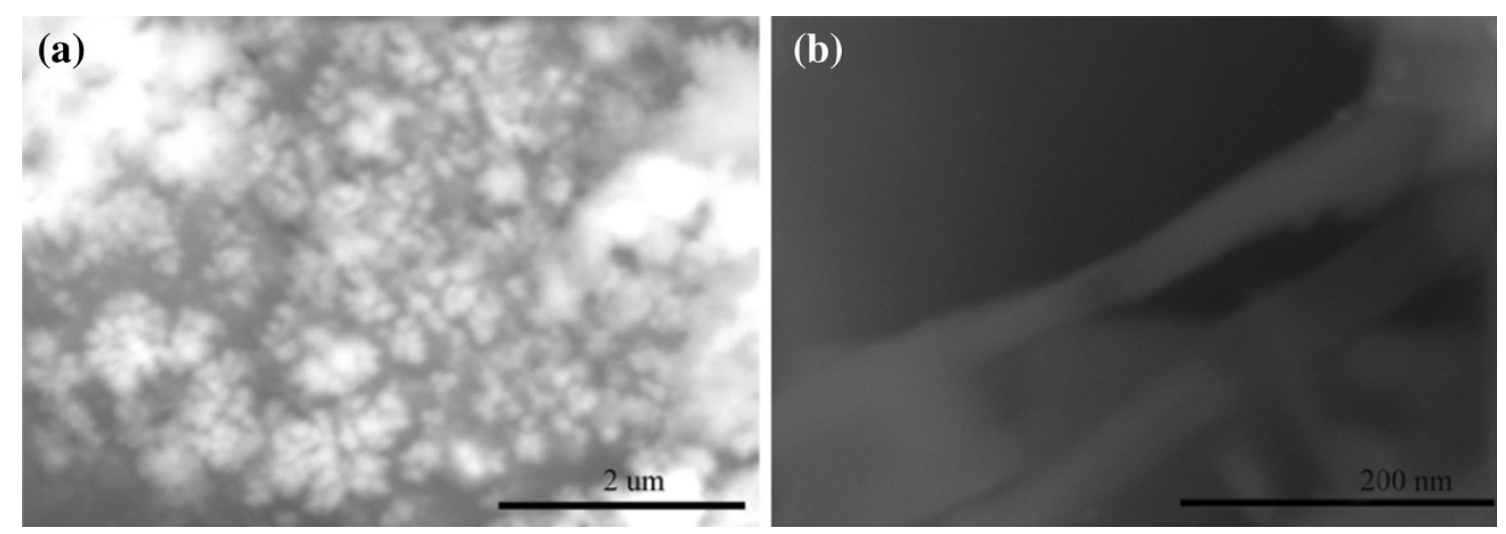

Fig. 3 a On-top SEM image of tungsten trioxide nanowires grown on PAA template b SEM image of tungsten trioxide nanowires grown on PAA template (side view)

$\mathrm{SnCl}_{2}+4 \mathrm{H}_{2} \mathrm{O} \stackrel{\mathrm{HCl}}{\longrightarrow} \mathrm{Sn}(\mathrm{OH})_{4}+\mathrm{Cl}_{2}+2 \mathrm{H}_{2}$

$\mathrm{Sn}(\mathrm{OH})_{4}$ reduced $\mathrm{PdCl}_{2}$ into $\mathrm{Pd}^{\circ}$

$\mathrm{Sn}(\mathrm{OH})_{4}+2 \mathrm{PdCl}_{2} \stackrel{\mathrm{HCl}}{\longrightarrow} 2 \mathrm{Pd}+\mathrm{SnCl}_{4}+2 \mathrm{H}_{2} \mathrm{O}+\mathrm{O}_{2}$

Here, we used small amount of $\mathrm{PdCl}_{2}$, since it was acting as a catalyst for reducing metal to be deposited. The standard electrode potential of $\mathrm{Pd}$ is $915 \mathrm{mV}$ [25]. Hydrazine reduces sodium tungstate by following mechanism:

$\mathrm{H}_{2} \mathrm{O} \rightarrow \mathrm{H}^{+}+\mathrm{OH}^{-}$,

$\mathrm{N}_{2} \mathrm{H}_{4}+4 \mathrm{OH}^{-} \rightarrow \mathrm{N}_{2} \uparrow+4 \mathrm{H}_{2} \mathrm{O}+4 \mathrm{e}^{-}$,

$\mathrm{W}^{+6}+3 \mathrm{e}^{-} \rightarrow \mathrm{W}^{+3} \quad \mathrm{E}^{\circ}=110 \mathrm{mV}$.

Standard reduction potential of tungsten is higher than that of reducing agent which is an important condition for reducing agent to have lower reduction potential than metallic ion to convert $\mathrm{W}^{+6}$ to $\mathrm{WO}_{3}$.

\section{SEM analysis of tungsten trioxide nanowire}

SEM images of $\mathrm{WO}_{3}$ nanowires are shown in Fig. 3. The PAA template with tungsten trioxide nanowires was dipped in $5 \mathrm{wt} \% \mathrm{NaOH}$ for $5 \mathrm{~min}$ at room temperature to dissolve aluminum. Then it was washed 2-3 times with deionized water. Figure $3 \mathrm{a}$ shows the bundles of tungsten trioxide nanowires with very small diameter, while Fig. $3 b$ demonstrates that the diameter of nanowires was about $50 \mathrm{~nm}$. These images depict that regular array of $\mathrm{WO}_{3}$ nanowires was formed by electroless deposition method with constant diameter throughout the length.

\section{$X R D$ analysis}

The structure of synthesized tungsten trioxide nanowires was further studied by XRD to confirm the oxidation sate and crystalline character. Figure 4 shows the XRD pattern of $\mathrm{WO}_{3}$ nanowires fabricated in nanopores of $\mathrm{Al}_{2} \mathrm{O}_{3}$. The peaks at $2 \theta$ values $30^{\circ}, 33^{\circ}, 44^{\circ}, 53^{\circ}$, and $63^{\circ}$ are the characteristics peaks of anodized alumina [26]. There is no broad peak centered at $25^{\circ}$, which shows that there is no amorphous alumina since such broad peak indicates that synthesized layer is highly disordered [27]. Accordingly, we may say that alumina is properly anodized.

The peaks at $2 \theta$ values $28^{\circ}, 35^{\circ}, 38^{\circ}, 54^{\circ}, 56^{\circ}$, and $65^{\circ}$ correspond to diffraction pattern of $\mathrm{WO}_{3}$ (JCPDS no 41-1230). These diffraction peaks of XRD pattern correspond to the (002), (012), (112), (222), and (023) reflections related to the cubic (Pm-3n) structure of $\mathrm{WO}_{3}$. Thus, XRD spectrum and SEM confirm the formation of tungsten trioxide nanowires by electroless deposition method.

\section{Conclusion}

PAA was synthesized by two-step anodization method with longer first anodization interval $\left(t_{1 \mathrm{AN}}=300 \mathrm{~min}\right.$; $\left.t_{2 \mathrm{AN}}=120 \mathrm{~min}\right)$ at $8 \mathrm{~mA} \mathrm{~cm}^{-2}, V_{\text {plateau }}=40 \mathrm{~V}, 0.3 \mathrm{M}$ oxalic acid, $5{ }^{\circ} \mathrm{C}$ temperature. SEM images depict uniform

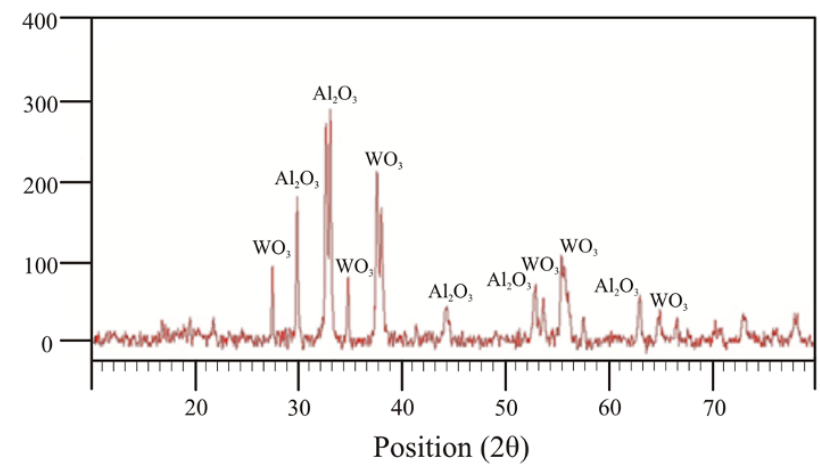

Fig. 4 XRD pattern of $\mathrm{WO}_{3} / \mathrm{Al}_{2} \mathrm{O}_{3}$ composite 
porous structure with long range hexagonal arrangements of pores which showed that self-ordering works under these conditions. The constant current density for anodization was found to be $8 \mathrm{~mA} \mathrm{~cm}^{-2}$ from current density versus time plot which also showed that for first anodization, the time interval required to attain constant current density at $40 \mathrm{~V}$ was greater than for the second anodization. The self-assembled template was used for the fabrication of 1D nanostructure of tungsten trioxide nanowires by electroless deposition method. The XRD and SEM results revealed that a uniform array of $\mathrm{WO}_{3}$ nanowires has been generated within pores of self-assembled PAA, and the diameter of the $\mathrm{WO}_{3}$ nanowire was similar to the diameter of PAA membrane, i.e., $50 \mathrm{~nm}$.

Acknowledgments We are grateful to PITMAEM, PCSIR for providing us facility for SEM analysis for morphological study of our samples. We are also grateful to Dr. Shahzad Naseem, Centre of Solid State Physics, University of the Punjab, Lahore for XRD analysis of our samples.

Open Access This article is distributed under the terms of the Creative Commons Attribution License which permits any use, distribution, and reproduction in any medium, provided the original author(s) and the source are credited.

\section{References}

1. Gorokh, G., Mozalev, A., Solovei, D., Khatko, V., Llobet, E., Correig, X.: Anodic formation of low aspect ratio porous alumina film for metal-oxide sensor application. Electrochim. Acta 52, 1771-1780 (2006)

2. Kang, H.J., Kim, D.J., Park, S.J., Yoo, J.B., Ryu, Y.S.: Controlled drug release using nanoporous anodic aluminum oxide on stent. Thin Solid Films 515, 5184-5187 (2007)

3. Briggs, E.P., Walpole, A.R., Wilshaw, P.R., Karlsson, M., Pålsgård, E.: Formation of highly adherent nano-porous alumina on Ti-based substrates: a novel bone implant coating. J. Mater. Sci. 15, 1021-1029 (2004)

4. Nielsch, K., Choi, J., Schwirn, K., Wehrspohn, R.B., Gösele, U.: Self-ordering regimes of porous alumina: the 10 porosity rule. Nano Lett. 2, 677-680 (2002)

5. Almawlawi, D., Bosnick, K.A., Osika, A., Moskovits, M.: Fabrication of nanometer-scale patterns by ion-milling with porous anodic alumina masks. Adv. Mater. 12, 1252-1257 (2000)

6. Adachi, M., Lockwood, D.: Self-organized nanoscale materials: from nanostructure science and technologies. In: Lockwood, D. (ed.), pp 296-312. New York: Springer (2006)

7. Masuda, H., Fukuda, K.: Ordered metal nanohole arrays made by a two-step replication of honeycomb structures of anodic alumina. Science 268, 1466-1468 (1995)

8. Chen, W., Yuan, J.H., Xia, X.H.: Characterization and manipulation of the electroosmotic flow in porous anodic alumina membranes. Anal. Chem. 77, 8102-8108 (2005)

9. Huczko, A.: Template-based synthesis of nanomaterials. Appl. Phys. A 70, 365-376 (2000)
10. Huber, C.A., Huber, T.E., Sadoqi, M., Lubin, J.A., Manalis, S., Prater, C.B.: Nanowire array composites. Science 263, 800-802 (1994)

11. Itoh, N., Kato, K., Tsuji, T., Hongo, M.: Preparation of a tubular anodic aluminum oxide membrane. J. Membr. Sci. 117, 189-196 (1996)

12. Belwalkar, A., Grasing, E., Van Geertruyden, W., Huang, Z., Misiolek, W.Z.: Effect of processing parameters on pore structure and thickness of anodic aluminum oxide (AAO) tubular membranes. J Membr. Sci. 319, 192-198 (2008)

13. Li, F., Zhang, L., Metzger, R.M.: On the growth of highly ordered pores in anodized aluminum oxide. Chem. Mater. 10, 2470-2480 (1998)

14. Gu, G., Zheng, B., Han, W.Q., Roth, S., Liu, J.: Tungsten oxide nanowires on tungsten substrates. J. Nano Lett. 2, 849-851 (2002)

15. Zhao, Z.G., Miyauchi, M.: Nanoporous-walled tungsten oxide nanotubes as highly active visible-light-driven photocatalysts. Angew. Chem. 120, 7159-7163 (2008)

16. Rout, C.S., Genesh, A., Govindaraja, A., Rao, C.N.R.: Sensors for the nitrogen oxides, $\mathrm{NO}, \mathrm{NO}_{2}$ and $\mathrm{N}_{2} \mathrm{O}$, based on $\mathrm{In}_{2} \mathrm{O}_{3}$ and $\mathrm{WO}_{3}$ nanowires. Appl. Phys. A 85, 241-246 (2006)

17. Zeng, W., Dong, C., Miao, B., Zhang, H., Sibo, X., Ding, X., Hussain, S.: Preparation, characterization and gas sensing properties of sub-miron porous $\mathrm{WO}_{3}$ spheres. Mater. Lett. 117, 41-44 (2014)

18. Cao, B., Chen, J., Tang, X., Zhou, W.: Growth of monoclinic $\mathrm{WO}_{3}$ nanowire array for highly sensitive $\mathrm{NO}_{2}$ detection. J. Mater. Chem. 19, 2323-2327 (2009)

19. Meng, D., Shaalan, N.M., Yamazaki, T., Kikuta, T.: Preparation of tungsten oxide nanowires and their application to $\mathrm{NO}_{2}$ sensing. Sens. Actuators B 169, 113-120 (2012)

20. Zhou, J., Ding, Y., Deng, S.Z., Gong, L., Xu, N.S., Wang, Z.L.: Three-dimensional tungsten oxide nanowire networks. Adv. Mater. 17, 2107-2110 (2005)

21. Ali, G., Ahmad, M., Akhter, J.I., Maqbool, M., Cho, S.O.: Novel structure formation at the bottom surface of porous anodic alumina fabricated by single step anodization process. Micron 41, 560-564 (2010)

22. Zaraska, L., Sulka, G.D., Szeremeta, J., Jaskuła, M.: Porous anodic alumina formed by anodization of aluminum alloy (AA1050) and high purity aluminum. Electrochim. Acta 55, 4377-4386 (2010)

23. Montero-Moreno, J.M., Sarret, M., Müller, C.: Self-ordered porous alumina by two-step anodizing at constant current: behaviour and evolution of the structure. Microporous Mesoporous Mater. 136, 68-74 (2010)

24. Ghorbani, M., Nasirpouri, F., Irajizad, A., Saedi, A.: On the growth sequence of highly ordered nanoporous anodic aluminium oxide. Mater. Des. 27, 983-988 (2006)

25. Yuan, X.Y., Xie, T., Wu, G.S., Lin, Y., Meng, G.W., Zhang, L.D.: Fabrication of Ni-W-P nanowire arrays by electroless deposition and magnetic studies. Phys. E 23, 75-80 (2004)

26. Lee, J., Kim, Y., Jang, H., Jung, U., Chung, W.: $\mathrm{Cr}_{2} \mathrm{O}_{3}$ sealing of anodized aluminium alloy by heat treatment. Procedia Eng. 10, 2803-2808 (2011)

27. Pionern, G.E.J., Ali, N., Fawecett, D.: Progress in nano-engineered anodic aluminium oxide memberane deveolpment. Materials 4, 487-526 (2011) 